\title{
FAMÍLIA, ESCOLA E PESSOA COM DEFICIÊNCIA
}

Ana Paula Cunha dos Santos Fernandes ${ }^{l}$

Nos últimos anos, por meio de pesquisas realizadas nas escolas, presenciamos professores de sala de recursos multifuncional relatando que não concluem suas atividades porque os alunos não comparecem. Os pais ou responsáveis não os levam. Outros professores reclamam que determinados pais são superprotetores e não lhes dão liberdade para trabalhar, quer em sala de aula comum, quer na sala de recursos multifuncional. Mas também presenciamos pais reclamando sobre os professores e o desenvolvimento escolar dos filhos. Assim surgiu a necessidade de discutirmos esta relação família e escola, mas neste trabalho a discussão se dará a partir das concepções dos professores.

A escola é um espaço onde se ensina e se aprende, e, segundo Oliveira (2004, p. 47), proporciona um caminho de mudança de postura por possibilitar o conhecimento da diversidade cultural, a mudança de mentalidade e a formação de novos comportamentos e atitudes frente a discriminação (socioeconômica, étnica e cultural).

Compreende-se que a escola é responsável por inúmeros compromissos e sua condição agrava quando associamos a este contexto a Política Nacional de Educação Especial na Perspectiva da Educação Inclusiva (BRASIL, 2008), a saber: assegurar a inclusão escolar de alunos com deficiência, transtornos globais do desenvolvimento e altas habilidades/superdotação; ofertar o atendimento educacional especializado; a formação específica para os professores; participação da família e da comunidade, dentre outros.

As discussões sobre o público-alvo da Educação Especial vão além da deficiência em si e buscam a validação do que fora proposto na LDB (BRASIL, 1996), onde ressalta-se que é dever da família, da escola e do Estado a responsabilidade pela formação do educando. A família é responsável legal pela educação de seus filhos com ou sem deficiência e a não participação/omissão dos pais é propulsora de uma futura ausência do aluno na escola, sala de aula comum e/ou Sala de Recursos Multifuncional - SRM. Há a necessidade de se estabelecer um equilíbrio entre as ações das partes em prol da pessoa com deficiência.

Não há intenção de discutir, neste artigo, concepção e tipos de família (mãe e filho (s), dois pais e filho (s), avós e neto (s), e outros), mas, sim, as responsabilidades e ações dignas à

\footnotetext{
${ }^{1}$ Doutorado em Educação Especial pela Universidade Federal de São Carlos (UFSCar). Professora no Programa de PósGraduação em Educação na Universidade do Estado do Pará (UEPA). Coordenadora do Grupo de Estudos e Pesquisas em Educação Especial na Amazônia (GEPEEAm/UEPA). E-mail: docenteapf@gmail.com
} 
família sobre a formação educacional e cidadã da criança e do adolescente para o seu completo desenvolvimento.

Considera-se que as crianças e adolescentes com deficiência necessitam de maior apoio de seus familiares para acompanhá-los e estimulá-los visando sua autonomia. Os que também usufruem da reabilitação têm em seus familiares o apoio mediador entre a Saúde e a Educação. Mediador no sentido de informar à escola as orientações, dadas pelo profissional da Saúde, e viceversa, sobre a criança e adolescente com deficiência, necessárias ou que contribuirão com a aprendizagem, a dignidade e qualidade de vida, ao que se perfaz à dignidade da pessoa humana.

\section{AS PRODUÇÕES NA ÁREA DA EDUCAÇÃO}

Este levantamento foi necessário para que se tenha um panorama sobre a discussão desta temática e seus desdobramentos. O descritor utilizado para a procura foi "família e educação especial" no banco de Teses da Capes. Surgiram 895.918 produções. Ajustamos a busca para área de concentração Educação e daí surgiram 6.413 resultados no primeiro momento, e, no segundo momento, 6.945 produções e, destes, 05 têm proximidade com a discussão proposta.

Quadro 1 - Instituição em que as dissertações e teses foram defendidas

\begin{tabular}{|l|l|l|l|l|}
\hline$N^{\mathbf{0}}$ & Produção & IES & Ano & Nível \\
\hline 1 & $\begin{array}{l}\text { EDUCAÇÃO ESPECIAL: CONSONÂNCIA E DISSONÂNCIA } \\
\text { NA RELAÇÃO FAMÍLIA E ESCOLA }\end{array}$ & UFF & 2000 & Mestrado \\
\hline 2 & $\begin{array}{l}\text { A EDUCAÇÃO DA CRIANÇA SURDA COM IMPLANTE } \\
\text { COCLEAR: REFLEX̃ES SOBRE A FAMÍLIA, A CLÍNICA E } \\
\text { A ESCOLA }\end{array}$ & UFES & 2013 & Mestrado \\
\hline 3 & $\begin{array}{l}\text { O QUE A FAMÍLIA DE CRIANÇAS COM DEFICIÊNCIA TEM } \\
\text { A NOS DIZER SOBRE A INCLUSÃO ESCOLAR DE SEUS }\end{array}$ & UFES & 2013 & Mestrado \\
\hline 4 & $\begin{array}{l}\text { ENVOLVIMENTO PARENTAL NO CONTEXTO DA } \\
\text { EDUCAÇÃO INFANTIL E SÉRIES INICIAIS DE ALUNOS } \\
\text { COM AUTISMO }\end{array}$ & UFSM & 2014 & Mestrado \\
\hline $\begin{array}{l}\text { RELAÇÕES FAMILIARES E ESCOLARIZAÇÃO DE IRMÃOS } \\
\text { ADOLESCENTES DE PESSOAS COM TEA }\end{array}$ & UFSM & 2015 & Mestrado \\
\hline
\end{tabular}

Fonte: Elaborado pela autora

Todas as produções identificadas no Banco de Teses da Capes afins ao objeto deste trabalho são em nível de Mestrado em Universidades públicas federais. Das produções, três foram defendidas na região sudeste e duas na região sul, no período de 2000 a 2015, porém há uma ausência de produção nos anos de 2001 a 2012, e são retomadas em 2013 a 2015. Face ao apresentado, considera-se que a discussão é recente e atualmente refere-se a duas regiões do país. A maioria das produções são posteriores a Política Nacional de Educação Especial na Perspectiva da 
Educação Inclusiva (BRASIL, 2008), um documento relevante sobre a discussão da Educação Especial no Brasil.

As produções identificadas no Quadro 1 possuem objetivos distintos, a saber: analisar os impactos do implante coclear na vida de uma criança surda que frequenta uma escola de Ensino Fundamental com uma política bilíngue; entender como a família da criança com deficiência, transtornos globais do desenvolvimento ou altas habilidades/superdotação percebe o processo de inclusão de seus filhos no contexto das salas comuns da educação infantil; entender como a família da criança com deficiência, transtornos globais do desenvolvimento ou altas habilidades/superdotação percebe o processo de inclusão de seus filhos no contexto das salas comuns da educação infantil; investigar as relações familiares e a escolarização de irmãos adolescentes de pessoas com TEA (Transtorno do Espectro Autista) a partir do ponto de vista dos irmãos, mães e professores.

Os objetivos transitam em questões diversas que envolvem a família e a pessoa com deficiência. Isto nos permite inferir que há um vasto campo a investigar e que podem contribuir e /ou fortalecer as discussões que envolvem a pessoa com deficiência, família e a escola.

Dentre os resultados destas produções, ressalta-se:

... em linhas gerais, que algumas famílias possuem dificuldades em aceitar um diagnóstico de deficiência, o que pode afetar e influenciar as relações familiares, percebemos um despreparo por parte da comunidade médica tanto em informar o diagnóstico quanto ao de realizar um acompanhamento a essas famílias. Diante disso, as famílias podem vivenciar sentimentos de insegurança quanto ao futuro social e escolar da criança. Por fim, as famílias apresentam um discurso de inclusão que não corresponde ao que definem como inclusão para seus filhos, entretanto, entendem a experiência escolar de seus filhos como algo positivo, mesmo diante dos desconhecimentos a respeito da política de educação inclusiva. (CRUZ, 2013, p. 8)

... entre as práticas de envolvimento parental, destaca-se a comunicação escola-casa, a qual é percebida pelas mães como insuficiente, enfraquecendo a relação de confiança entre esses contextos. Quanto ao apoio da escola às mães para favorecer a aprendizagem dos filhos, observou-se que as orientações dos professores são mais centradas nos déficits dos alunos do que em seus recursos... (VARGAS, 2014, p. 9)

... mostram que os irmãos apresentam dificuldades de interação social com colegas e amigos, assim como uma alta exigência para com seu desempenho escolar e familiar, assumindo responsabilidades com relação ao futuro para além do seu papel como irmão. Apesar do alto desempenho escolar constatado, o isolamento social familiar pode contribuir para a vulnerabilidade desta população (RODRIGUES, 2015, p. 7) 
Os resultados apresentados acima ainda são emergentes e nos permite fruir outras problemáticas. Por fim, as produções aqui apresentadas somam-se na discussão deste trabalho com relevante aporte teórico.

\section{METODOLOGIA}

Esta pesquisa é de cunho qualitativo pela contemporaneidade da discussão, e concordante a Chizzotti (2006), destacamos:

Novos temas e problemas, originários de classe, gênero, etnia, raça, culturas, trazem novas questões teóricas e metodologias aos estudos qualitativos. Uma confluência de tendências, disciplinas científicas, processos analíticos, métodos e estratégias aportam à pesquisa qualitativa criando um campo amplo de debates sobre o estatuto da pesquisa. (CHIZZOTTI, 2006, p. 54)

Realizamos o levantamento das produções no Banco de Teses da CAPES sobre a temática na área da Educação. Sobre este levantamento, registramos:

Ao tratar da pesquisa bibliográfica é importante destacar que a mesma é sempre realizada para fundamentar, teoricamente, o objeto de estudo, contribuindo com elementos que subsidiam a análise futura dos dados obtidos. Portanto, difere da revisão bibliográfica, uma vez que vai além da simples observação de dados contidos nas fontes pesquisadas, pois imprime sobre eles a teoria, a compreensão crítica do significado neles existente (LIMA; MIOTO, 2007).

Optamos pela entrevista semiestruturada, à qual elencou-se informações pessoais e profissionais. Optou-se por

“... recolher dados descritivos na linguagem do próprio sujeito, permitindo ao investigador desenvolver intuitivamente uma ideia sobre a maneira como os sujeitos interpretam aspectos do mundo" (BOGDAN; BIKLEN, 1994, p. 134)

A sistematização e análise dos dados se deu por categorias construídas desde a fase inicial da pesquisa:

em uma ação de organização lógica dos dados coletados, viabilizando uma estrutura organizadamente integrada. A partir das categorias de análises construídas é possível ao pesquisador refletir criticamente sobre a análise das informações obtidas na investigação. (OLIVEIRA; MOTA NETO, 2011, p.163)

As categorias analíticas podem ser iniciais ou emergentes. As categorias analíticas iniciais surgem nas primeiras leituras sobre o tema de estudo. São conceitos que estão na base das discussões teóricas em torno do objeto de estudo (OLIVEIRA; MOTA NETO, 2011). Enquanto que as categorias analíticas emergentes surgem no desenvolvimento da pesquisa e podem ser oriundas tanto da leitura bibliográfica como do processo de coleta dos dados (OLIVEIRA; MOTA NETO, 2011). 
Neste trabalho, a categoria analítica é a Educação Especial; a categoria temática é a Família e as unidades temáticas são: isolamento dos alunos com deficiência, participação da família nas reuniões com as professoras de SRM, reunião dos pais na escola e o problema financeiro.

A pesquisa foi aprovada pelo Comitê de Ética (CAAE: 11054512. 0. 0000.5504) e, aos entrevistados, foi solicitada a confirmação e a assinatura do Termo de Consentimento Livre e Esclarecido, preservando sua identidade com nomes fictícios; e, sobre o locus, foi-nos permitido pela Secretaria de Educação desenvolver a pesquisa.

A pesquisa foi realizada em cinco escolas e duas unidades pedagógicas da Secretaria Municipal de Educação, em quatro ilhas de Belém: Caratateua, Combu, Cotijuba e Mosqueiro.

Quanto aos sujeitos, foram entrevistados coordenadores pedagógicos, professoras de Sala de Recursos Multifuncionais (SRM) e professores de sala de aula comum, perfazendo um total de treze sujeitos entrevistados. Todos possuem pós-graduação lato sensu e, a minoria, stricto senso.

Os critérios estipulados para a escolha dos professores foram: ser professor de classe comum ou sala de recursos multifuncional do ensino fundamental da rede municipal de ensino; ter aluno com deficiência e estar disponível para participar da pesquisa.

Resultados e Discussão

Sobre os resultados encontrados, ressaltamos que são sobre a relação família-escola ou que os perpassam, e, assim, destacamos:

- Isolamento dos alunos: apesar da receptividade, do bem receber e da boa convivência informada por alguns entrevistados, outros docentes apontam para situação de isolamento, por parte de alguns alunos com deficiência e outros problemas.

\footnotetext{
A escola ainda não está preparada para receber os alunos com NEE, ainda falta muito. A gente escuta isso dos professores, da coordenação, do diretor e eles dizem isso para gente que falta, das angústias deles, eles dizem que não estão preparados, que eles não tiveram isso na faculdade, que para eles está sendo muito difícil e precisam de ajuda. Todos os professores. É comum, a mesma coisa. (PROF ${ }^{a}$ MEIRE-SRM)
}

O discurso de "ausência de preparação" não justifica não poder receber os alunos com deficiência. Há a necessidade de intervenção e/ou atuação da família para que se minimize qualquer tipo de preconceito ou exclusão na escola. Para tanto, os pais precisam acompanhar a realidade do cotidiano escolar e do comportamento de seus filhos.

Campos (2011) descreve que estudos sobre a relação família-escola tem apontado que, quanto maior o vínculo dos pais ou responsáveis estabelecidos com o processo de escolarização dos filhos, maiores são as chances dos filhos obterem bom desempenho escolar e, até mesmo, de 
alcançar os níveis mais elevados do sistema de ensino. Assim, faz-se necessário que a família assuma também sua condição de responsabilidade no processo educacional e social do aluno.

Porém, para Altiere (2006), o vínculo emocional entre os membros familiares define o grau de coesão familiar. Portanto, o grau de coesão (estruturado e flexível) e a adaptabilidade (potencial de mudança, adaptação) de uma família repercute diretamente na eficiência de seu funcionamento. Assim, uma família com estas características possui melhor condição de acompanhar seu filho com deficiência na escola e contribuir com o processo educacional.

A prof ${ }^{a}$ Maria explica que há, sim, na escola em que atua, uma preparação do professor para receber o aluno com deficiência e como os alunos entram na escola na educação infantil e permanecem até o ensino médio, não há problemas de interação entre os educandos e os professores.

\begin{abstract}
Hoje em dia, a gente trabalha com o professor, a gente avisa, informa qual a deficiência, esclarece e aí fica à cargo do professor trabalhar a turma, a sensibilização da turma. Então, felizmente, como a maioria entra lá na educação infantil, nossos alunos, a grande maioria, entram com 4 anos de idade e ficam até o ensino médio, os pais não os retiram. É fácil porque a criança pequena a gente trabalha ali aquela sensibilidade no início, eles ficam muito próximo, se ajudam... quando eles já vão para outras turmas, eles já são crianças que já tem o contato com os mesmos colegas já de muito tempo. Então eles acabam não tendo muita dificuldade.... E o aluno novo com deficiência que chega não tem esta estranheza entre eles. (PROF ${ }^{a}$ MARIA-SRM)
\end{abstract}

Martins (2009, p. 159) apresenta dados de sua pesquisa com professores em Natal/RN, nos quais evidencia que, apesar dos esforços feitos pelos sistemas públicos na formação e recursos humanos, ainda há necessidade de maior investimento na preparação de profissionais para atuação com a diversidade do alunado, em sala de aula comum.

Cabe aos gestores organizar a escola para garantir o acesso e permanência dos alunos com deficiência e, ainda, eliminar qualquer barreira (BRASIL, 2015, Art. $3^{\circ}$ ):

barreiras atitudinais: atitudes ou comportamentos que impeçam ou prejudiquem a participação social da pessoa com deficiência em igualdade de condições e oportunidades com as demais pessoas.

Por fim, deve-se

assegurar sistema educacional inclusivo em todos os níveis e aprendizado ao longo de toda a vida, de forma a alcançar o máximo desenvolvimento possível de seus talentos e habilidades físicas, sensoriais, intelectuais e sociais, segundo suas características, interesses e necessidades de aprendizagem (BRASIL, 2015, Art. 27).

- Famílias nas reuniões/SRM: a Prof ${ }^{a}$ Meire ressalta a participação da família nas reuniões com as professoras da SRM.

A gente tem sorte com família aqui em Mosqueiro porque a família participa, os pais participam, os pais indagam. A gente sempre realiza reuniões eles estão sempre presentes. Muito participativos, muito mesmo. A gente tem fotos dos pais nas reuniões. Quando é 
preciso a gente faz visita domiciliar, a gente precisa saber como é o cotidiano dele. Quais são os elementos atribuídos a ele que possam vir a contribuir com esse aluno. Ou então por falta no AEE. (PROF ${ }^{\mathrm{a}}$ MEIRE-SRM)

Para Kaloustian (1988), a família desempenha um papel fundamental na educação, pois é em seu espaço que são absorvidos os valores éticos e humanitários e se aprofundam os laços de solidariedade. Laluvein (2001, p.17) destaca que:

Os pais são agentes fundamentais na educação de seus filhos, com acesso a conhecimento e da informação a partir de uma variedade de alternativas além dos limites da escola.... Alguns pais estão preparados para desafiar, empowerment, e se necessário entrar em conflito com o professor/autoridade escolar.

A prof ${ }^{a}$ Luzia evidencia que as reuniões com os pais são à parte das atividades da escola:

Não sei qual a intensidade da participação deles. Está dentro do nosso trabalho do AEE fazer reunião com esses pais, orientar esses pais. Mas eles participam também das atividades da escola. Não são todos, mas a maioria participa. (PROFa LUZIA-SRM)

- Reunião de pais na Escola e o problema financeiro das famílias: na ilha de Mosqueiro, a reunião com os pais e os professores de SRM é uma atividade à parte da escola, algumas escolas preparam café da manhã para receber os pais permitindo que estes relatem as mudanças que visualizam no filho, no processo de aprendizagem, na escola. Mas há escolas, nesta e em outras ilhas, que não vivenciam isso. A prof ${ }^{a}$ Carla (SALA COMUM) denuncia "participam, mas, muitos não estão vindo. Às vezes as meninas (profas da SRM) chamam para cá, não vem. Há ausência dos pais”. E o prof José (SALA COMUM) enfatiza: "os pais são muito ausentes da escola tanto é que estou chamando".

Ressalta-se que a responsabilidade dos pais para com o filho é em qualquer ambiente, escolar ou não, e independente de condição financeira. Prof ${ }^{a}$ Ana revela sua preocupação pela condição do aluno com deficiência matriculado na pré-escola:

A família está sempre por aqui. No caso do João a família tem problemas financeiros graves, mas, tentam fazer o que podem. Apesar de...(sussurrou violência)... já tive relatos de vizinhança com relação ao João que ele fica muito solto, o que foi problema para mim em sala de aula, ele se sentia preso. E disseram que ele foge de casa, fica na rua e quem pega é vizinho, é o que muitas pessoas relatam. (PROFa ANA-SALA COMUM)

Sobre a escola e a violência, Pino destaca:

se a escola, como outras instituições sociais, muito pode fazer para incentivar a compreensão por parte dos alunos dos valores realmente humanos, livres de qualquer afetação moralista, capazes de fornecer razões para não optar pelo uso da violência no intuito de viver uma sociabilidade humana, ela tem também que repensar sua função numa sociedade em constante mudança (PINO, 2007, p. 782)

O Art.18 do Estatuto da Criança e do Adolescente (BRASIL, 1990) destaca que " é dever de todos velar pela dignidade da criança e do adolescente, pondo-o a salvo de qualquer tratamento desumano, violento, aterrorizante, vexatório ou constrangedor”. Há a necessidade de diálogo sobre 
a defesa de direitos das crianças e adolescentes e a escola poderia ser este canal junto à comunidade em geral.

Destaca-se ainda, no Art. 227 da Constituição Federal, que:

É dever da família, da sociedade e do Estado, assegurar à criança e ao adolescente, com absoluta prioridade, o direito à vida, à saúde, à alimentação, à educação, ao lazer, à profissionalização, à cultura, à dignidade, ao respeito, à liberdade, e a convivência familiar e comunitária, além de colocá-los a salvo de toda forma de negligência, exploração, violência, crueldade e opressão. (BRASIL, 1988)

A prof ${ }^{a}$ Maria evidencia que faz contato com os pais independe das reuniões. Após conversar com o aluno, se considerar relevante, providencia o contato/diálogo:

\begin{abstract}
Estou sempre chamando os pais, monto as reuniões, converso. Dependendo do diálogo com o aluno, eu estou sempre chamando e mantendo esse contato mais próximo com a família. É para orientar. Tem uma aluna lá que tem problema psiquiátrico, assim, bem claro, em conversa identifica. Só que ela não tem laudo, tem só um documento que uma psiquiatra deu, só disse as dificuldades. Ela é jovem, já tem 20 anos de idade e todo atendimento ela relata uma dificuldade para mãe: briga, umas confusões; vira e mexe eu estou chamando essa mãe, para tentar minimizar, mostrar para ela a forma de trabalhar. Mas é um caso mais complicado de relação familiar. (PROFa MARIA-SRM)
\end{abstract}

Não havendo reuniões na escola com os pais, a professora atribui a si a responsabilidade pelo contato e diálogo com eles: "Na família ainda não tive esse privilégio, mas estou tentando me organizar para ir esta semana na casa”, relata prof ' Joelma. E ainda sobre violência e outras questões na escola, ressalta:

a escola é um espaço que precisa de muita atenção, precisa de um compromisso total de todos nós professores que nesse momento em que a escola se encontra, com muita necessidade, precisam discutir muitas coisas: comportamento, violência, tolerância. (PROF ${ }^{\mathrm{a}}$ JOELMA-SRM)

Os entrevistados explicaram que há pais que participam das reuniões escolares e às reuniões com as professoras da SRM; a presença da mãe na escola é mais evidente que a dos demais familiares; em alguns casos, ocorre a participação dos pais nas reuniões da escola, mas evitam o contato com a equipe da SRM; há situações que extrapolam os muros da escola com questões de cunho social. É relevante o apoio da família, mas sem a superproteção, que é a condição avessa da nulidade familiar, como destaca o prof Pedro (SALA COMUM): “As famílias vêm. Eu vejo que elas sempre estão aqui. Às vezes, até se questiona, porque ao meu ver, não se desenvolve porque é muito paparicado".

Jannuzzi (1985) ressalta que é fundamental que o trabalho para superar (preconceito e discriminação) se inicie dentro da família e da forma mais ampliada possível, não devendo se reduzir apenas à figura materna, como tradicionalmente é feito. A superação enfatizada pela autora 
é primordial para a relação família-escola, e, principalmente, para a autoestima, segurança, dignidade e cidadania da pessoa com deficiência em qualquer nível escolar.

É preciso cautela nesta discussão entre família e escola. É preciso mediar as relações priorizando uma relação harmoniosa e não de oposição/conflito. Cruz (2013) apresenta uma síntese sobre isso:

na educação, discute-se o papel da família no processo de escolarização da criança, porém muitos são os questionamentos e julgamentos quanto ao papel que a família deve desempenhar no processo educativo dos filhos. Por outro lado, a escola também tem seu papel questionado e o que se percebe é um grande desencontro entre família e escola no que tange ao processo de escolarização das crianças. Cunha $(2000$, p. 450$)$ vai além quando afirma que "a escola se tornou mais do que uma simples instituição de apoio à família: ela posicionou-se contra a família [...] e ao longo de sua história, foi incorporando saberes científicos em oposição aos saberes domésticos tradicionais”. (CRUZ, 2013, p.16)

A orientação à família perpassa pelos direitos das pessoas com deficiência e as professoras de Sala de Recursos Multifuncional informam que o Governo Federal disponibilizou, em 2011, o Plano Nacional dos Direitos da Pessoa com Deficiência - Viver sem Limites, o qual apresenta os benefícios e assistências disponíveis às pessoas com deficiência e estas informações são repassadas aos pais. Dentre as divulgações deste Plano, está o Programa BPC na Escola (p. 15), que é uma ação interministerial que envolve o Ministério da Educação (MEC), o Ministério da Saúde (MS), o Ministério do Desenvolvimento Social e Combate à Fome (MDS) e a Secretaria de Direitos Humanos (SDH). Este Programa está voltado às crianças e adolescentes com deficiência (0 a 18 anos) que recebem o Benefício de Prestação Continuada (BPC).

Neste plano, para o recebimento do benefício (p. 16), é necessário que o aluno esteja cadastrado no CadÚnico e ainda saber se o município já aderiu ao programa, indo à Secretaria de Educação ou à Secretaria Municipal de Assistência Social. Assim, é possível que uns alunos recebam e outros não. Prof ${ }^{a}$ Meire (SRM) relata que alguns têm, outros não têm. Enquanto isso, prof ${ }^{a}$ Joelma (SRM) informa que um de seus alunos já recebe o auxílio; a outra aluna ainda não, mas a escola informa que a mãe da aluna se nega a receber orientação da Assistência Social.

O João recebe o auxílio, a Cris tem um grave problema de que alguém fez a mãe assinar um documento abrindo mão, mas a escola está fazendo essa ponte. A mãe tem se negado a receber orientação da Assistente Social. (PROF JOELMA-SRM)

A escola contribui com as orientações aos pais e responsáveis, embora, atualmente, este contato esteja restrito à SRM, como informado pela prof ${ }^{a}$ Maria-SRM:

... alguns a gente orienta, a Assistente Social verifica se é caso que tem direito e encaminha. A gente dá toda a orientação. Alguns já recebem, já conseguiram, o benefício. Para o CRAS, a gente encaminha, sempre que é necessário a gente faz o encaminhamento via Assistente Social. Ela verifica e manda. Mas, não frequenta muito o CRAS, só uns poucos casos. (PROF ${ }^{a}$ MARIA-SRM) 
Até para os que necessitam de laudo médico, a professora da SRM tem se disponibilizado e viabilizado o acesso:

O posto de saúde em si, eu mando, geralmente, um relatório para mãe levar para o médico que ela me diz que não vai saber explicar. A gente não pode. A instituição geralmente diz logo que é saúde, só aceita se vir encaminhado do posto. Não aceita encaminhamento da escola. (PROF ${ }^{a}$ MARIA-SRM)

A prof ${ }^{a}$ Luzia destaca que um dos motivos dos pais não receberem o auxílio é porque não possuem laudo e outros documentos. Outros, apesar de receberem o auxílio, continuam cobrando da escola recursos financeiros e sendo que o papel da escola é o de orientar a busca de auxílio e não dar dinheiro para as necessidades dos educandos.

Muitos recebem. Outros não, porque não tem laudo. Como vai receber? Alguns a gente percebe que está bem asseado, bem vestido, tem seu material, mas outros...por exemplo tem mãe que recebe, vem para o AEE e quer que a gente dê o dinheiro do ônibus. Hoje eu chamei a atenção das duas porque eu vi a mãe pedir para uma prof ${ }^{a}$ de SRM, e chamei e disse para professora não fazer mais isso. Eu tinha marcado com essa mãe para eu continuar a avaliação do filho dela na segunda-feira, eu tive um problema e tive que ir lá para o Angelus, fui fazer a avaliação dos alunos. Quando cheguei lá, a mãe tinha vindo para cá e tinha esquecido de desmarcar, e a prof ${ }^{a}$ também esqueceu de desmarcar, e quando ela foi daqui ela pediu para outra professora que ela só ia daqui quando a professora desse o dinheiro. A mãe recebe benefício e o menino recebe bolsa escola então não tem porquê. A gente pode até dar, mas, tem situações. Nós tivemos uma situação aqui que realmente são situações de risco assim, situações de pobreza, de pessoas que precisam de uma orientação. É outra situação. (PROF ${ }^{a}$ MARIA-SRM)

$\mathrm{O}$ fato da mãe pedir dinheiro às professoras revela a ideia de muitas pessoas ainda hoje que a pessoa com deficiência precisa de caridade. É preciso desconstruir a ideia de que pessoa com deficiência é "pobre coitado". A pessoa com deficiência hoje não vive o assistencialismo relatado por Fernandes (2015), em sua tese de doutorado, em que destaca que desde o início da República, o Brasil circunda o assistencialismo, porém antes não nominado como tal, mas com ações comprovadas por meio de instituições filantrópicas e doação por pessoa física. Na perspectiva legal, de Inclusão, não se considera o assistencialismo, mas, o direito. A Pessoa com Deficiência é pessoa com direito, e não deveria ter mais a caridade ou benevolência, porém ainda paira no imaginário de alguns que quem recebe o benefício financeiro do governo federal é necessitado ao extremo, é miserável, sem condição, sem perspectiva, dentre outros. Ou que ainda se deva "doar" dinheiro para suas atividades elementares.

Mais uma vez, ressalta-se a relevância da parceria família/escola em favor da pessoa com deficiência, como revelado por Cambruzzi (1998, p.90) 
é fator fundamental a parceria escola/família, pois são agentes de transformação em termos individuais e, coletivamente, favorecem a mudança de visão, ainda distorcida, que a sociedade tem a respeito do deficiente ${ }^{2}$.

Ressalta-se que a relação entre família e escola é fundamental para um ambiente mais seguro e tranquilo que propicie o desenvolvimento escolar e pessoal do aluno com deficiência.

Considerações finais

Este trabalho objetivou analisar a relação família-escola na formação do aluno com deficiência por meio das percepções dos professores. Destaca-se o resultado deste trabalho, a saber: há a necessidade de apresentar aos pais a importância da participação da família, a interação com a vida da pessoa com deficiência em casa, na escola e onde mais houver possibilidade. Há de se evidenciar que as pessoas com deficiência também nasceram para ter vida, vida social, vida profissional, e não devem ser criadas apenas para a morte. A família e a escola podem colaborar muito com este processo de vida. Ainda há a necessidade de a escola articular atividades e responsabilidades com os pais e/ou responsáveis, dentre outros.

Os limites sobre a discussão desta temática na área da Educação/Educação Especial concentram-se na pouca produção em nível de pós-graduação e na continuidade das problematizações.

Por fim, almeja-se que as discussões preliminares aqui apresentadas sejam debatidas em outras instâncias e pesquisas sejam instigadas e/ou motivadas. Assim como ser debatido, amplamente, nos ambientes escolares.

\section{Referências}

ALTIERE, M. J. Family Functioning and Coping Behaviors in Parents of Children with Autism. 2006. Disponível em: http://commons.emich.edu/cgi/viewcontent.cgi?article=1053\&context=theses $>$. Acesso em: 12 / $01 / 2017$.

BOGDAN, R. C.; BIKLEN, S. K. 1994. Investigação qualitativa em educação. Porto: Porto Editora, 1994.

BRASIL. Lei no 9394 de 1996. Estabelece as diretrizes da educação nacional. Disponível em:<http://www.planalto.gov.br/ccivil_03/leis/19394.htm>. Acesso em: 04/ 02/ 2017. - Ministério da Educação. Política Nacional de Educação Especial na Perspectiva da Educação Inclusiva. Brasília: MEC, 2008. Disponível em: <http://www.mec.gov.br>. Acesso em: 11/ 12/ 2016.

\footnotetext{
${ }^{2}$ Terminologia original utilizada pelo autor. 
. Decreto $\mathbf{n}^{\mathbf{0}}$ 7.612. Institui o Plano Nacional dos Direitos da Pessoa com - Plano Viver sem Limite. 2011. Disponível em: <http://www.planalto.gov.br/ccivil_03/_Ato2011-2014/2011/Decreto/D7612.htm>. Acesso em: 05/ $05 / 2016$.

. Estatuto da Criança e do Adolescente - ECA. Lei nº 8.069. Brasília, 1990.

Constituição Federal. Brasília, 1988.

$\overline{\mathrm{CAPES}}$. Banco de Teses. Disponível em: <http://bancodeteses.capes.gov.br>. Acesso em: 28/01/ 2017.

CAMBRUZZI, R. C. S. Estimulação Essencial ao portador de Surdez. In: III CONGRESSO IBERO-AMERICANO DE EDUCAÇÃO ESPECIAL, 1998, Foz do Iguaçu, Anais... Foz do Iguaçu - PR: Qualidade, 1998, volume 3, p. 86-90.

CAMPOS, A. R. Família e Escola: um olhar histórico sobre as origens dessa relação no contexto educacional brasileiro. Disponível em: <http://www.ufsj.edu.br/portal2repositorio/File/vertentes/v.\%2019\%20n.\%202/Alexandra_Campos.pdf >. Acesso em: 12 de Fevereiro de 2016.

CARNEIRO, R. K. S. Educação Especial: consonância e dissonância na relação família e escola. 177 p. Niterói, RJ. Dissertação de Mestrado. Universidade Federal Fluminense, 2000.

CARVALHO, E. Escola como extensão da família ou família como extensão da escola? $O$ dever de casa e as relações família-escola. Revista Brasileira de Educação, Rio de Janeiro, vol. 25, p. 94-104, 2004.

CHIZZOTTI, A. Pesquisa qualitativa em Ciências Humanas e Sociais. Petrópolis, Vozes, 2006.

CRUZ, D. M. M. O que a família de crianças com deficiência tem a nos dizer sobre a inclusão escolar de seus filhos? 151 p.. Vitória, ES. Dissertação de Mestrado. Universidade Federal do Espírito Santo, 2013.

FERNANDES, A. P. C. S. A Escolarização da Pessoa com Deficiência em Comunidades Ribeirinhas da Amazônia Paraense. 280 p. Tese de Doutorado. Universidade Federal de São Carlos, São Carlos, 2015.

IBGE. Censo 2010. Disponível em: <www.ibge.gov.br>. Acesso em: 22/ 08/ 2013.

JANNUZZI, G. S. M. A luta pela educação do deficiente mental no Brasil. Campinas, Autores Associados, 1985. 1988.

KAlOUStian, S. M. (org.). Família brasileira, a base de tudo. São Paulo, Cortez,

LALUVEIN, J. Parents and teachers talking in primary schools. Educate - The Journal of Doctoral Research in Education, vol. 1, n.1, p. 16-22, 2001.

LIMA, T. C. S.; MIOTO, R. C. T. Procedimentos metodológicos na construção do conhecimento científico: a pesquisa bibliográfica. Rev. Katál. Florianópolis, 10 (número especial), p. 37-45, 2007.

MARTINS, L. A. R. Formação continuada de docentes: algumas reflexões sobre a sua contribuição para a educação inclusiva. In: Claudio Roberto, BAPTISTA; Denise Meyrelles, JESUS. Avanços em políticas de inclusão: o contexto da educação especial no Brasil e em outros países. Porto Alegre: Mediação, 2009, p. 153-173.

OLIVEIRA, I. A. Saberes, imaginários e representações na educação especial: a problemática ética da "diferença" e da exclusão social. Rio de Janeiro, Vozes, 2004.

OLIVEIRA, Ivanilde Apoluceno de; MOTA NETO, João Colares. A construção de categorias de análise na pesquisa em educação. In: MARCONDES, Maria Inês; OLIVEIRA, 
Ivanilde Apoluceno de; TEIXEIRA, Elizabeth. (Org.). Abordagens Teóricas e Construções Metodológicas na Pesquisa em Educação. Belém: EDUEPA, 2011.

PINO, A. Violência, educação e sociedade: um olhar sobre o Brasil contemporâneo. Educação \& Sociologia, Campinas, vol. 28, n.100, p. 763-785, 2007.

RODRIGUES, T. P. Relações familiares e escolarização de irmãos adolescentes de pessoas com TEA. 91 p. Santa Maria, RS. Dissertação de Mestrado. Universidade Federal de Santa Maria, 2015.

SILVA, J. A. S. A educação da criança surda com implante coclear: reflexões sobre a família, a clínica e a escola. 204 p. Vitória, ES. Dissertação de Mestrado. Universidade Federal do Espírito Santo, 2013.

VARGAS, R. M. Envolvimento parental no contexto da educação infantil e séries iniciais de alunos com autismo. 113 p. Santa Maria, RS. Dissertação de Mestrado. Universidade Federal de Santa Maria, 2014. 


\section{RESUMO}

Objetiva-se analisar a relação família-escola na formação da pessoa com deficiência a partir das concepções dos professores. Como a família e a escola contribuem na formação da pessoa com deficiência? Configura-se como pesquisa qualitativa, e seguiu o seguinte delineamento: levantamento bibliográfico, entrevistas semiestruturada, sistematização e análise dos dados. O estudo foi realizado com coordenadores pedagógicos, professores de sala de aula comum e sala de recursos multifuncional, em cinco escolas e duas unidades pedagógicas de Belém. Sobre os resultados: em algumas escolas a família participa das reuniões com os professores de SRM à parte da escola, e, em outras, não comparece e alega falta de condição financeira; uma professora destaca a questão da violência.

Palavras-chave: Educação Especial. Família. Escola.

\section{FAMILY, SCHOOL AND HANDICCAPED PEOPLE}

Abstract: The aim of this paper is to analyze the relationship family-school on education of handicapped people from the conceptions of the teachers. So how family and school contribute to the education of handicapped people? The research is qualitative, which procedures were bibliographic search; semi-structured interviews; systematization and data analysis. The research was it has participated of pedagogical coordinators, teachers of SRM and teachers of regular classroom, performed in 5 schools and 2 pedagogical units located at Belém. The results pointed out that: in some schools, the family participates in meetings with SRM teachers outside the school, and in others, it does not attend and claims lack of financial condition; a teacher highlights the issue of violence with the child.

Keywords: Special Education. Family. School.

\section{FAMILIA, ESCUELA Y PERSONA CON DISCAPACIDAD}

Resumen: Se pretende analizar la relación familia-escuela en la formación de la persona con discapacidad a partir de las concepciones de los profesores. Así, se pregunta: ¿cómo la familia y la escuela contribuyen para la formación de la persona con discapacidad? Se configura como una investigación cualitativa, los procedimientos son: búsqueda bibliográfica, entrevistas semiestructuradas, sistematización y análisis de datos. El estudio se realizó coordinadores pedagógicos, profesores de la sala de clase regular y de la SRM, en cinco escuelas y dos unidades pedagógicas de Belém. Los resultados apuntan: en algunas escuelas la familia participa de las reuniones con los profesores de SRM aparte de la escuela, y, en otras, no comparece y alega falta de condición financiera; una profa. destaca la cuestión de la violencia.

Palabras-clave: Educación Especial. Familia. Escuela. 